\title{
Evaluación de costo-utilidad de un programa de antención integral de niños con asma en un país de ingresos medios
}

Duenas-Meza E, Torres-Duque CA, Karpf E, Afanador F, Barón O, Angarita O, Pachón A, Jurado J, Giraldo-Cadavid LF. Fundación Neumológica Colombiana

INTRODUCCIÓNY OBJETIVO

Existen muy pocos estudios que evalúen el impacto económico de los programas integrales de asma en Latinoamérica. Objetivo :evaluar la costo-utilidad de un programa de atención integral de niños con asma en comparación con el cuidado habitual por fuera del programa.

\section{MATERIALES Y MÉTODOS}

Modelo de Markov probabilistico para evaluar la costo-utilidad del cuidado integral brindado dentro del Programa ASMAIRE Infantil (PAI). Dos brazos: uno terapia estándar más el cuidado integral del PAl y el otro terapia estándar y cuidado por la consulta de Neumologia Pediátrica fuera del PAl. El modelo de Markov incluyó cuatro estados: Asma controlada (AC), Exacerbación severa(ES), Exacerbación no severa(ENS), Muerte(M). Horizonte temporal 15 años. Las probabilidades de transición entre control y ES y ENS se obtuvieron del registro del PAI, de control a M de los datos de mortalidad de los registros estadisticos (DANE) y a partir de un meta-análisis que midió la mortalidad en exacerbaciones de asma. Costos: Los recursos de salud, asi como las consecuencias fueron aplicados para cada uno de los estados determinando los costos. Valor de los medicamentos: de acuerdo con el Instituto de Evaluación Tecnológica en Salud, los costos de atención médica se obtuvieron calculando los costos directos de la atención a partir de la facturación en urgencias, hospitalización y cuidado intensivo. Análisis de sensibilidad probabilistico para capturar la incertidumbre de efectividad, utilidades y costos en el modelo.

\section{RESULTADOS}

En comparación con el grupo de cuidado usual, el grupo PAI tiene un costo incremental de COP $\$ 1,543,384$ por paciente y una efectividad incremental en 0,046 AVACs por paciente, se traduce en una razón costo utilidad incremental (RCUI) de COP $\$ 33,753,817$ por AVAC ganado. EI PAI fue costo-útil (más efectivo y con un costo por debajo del umbral de disponibilidad a pagar) en un $67 \%$ de las simulaciones y dominante (más efectivo y menos costoso) en $27 \%$ de las simulaciones frente a la cohorte que no hacia parte del programa

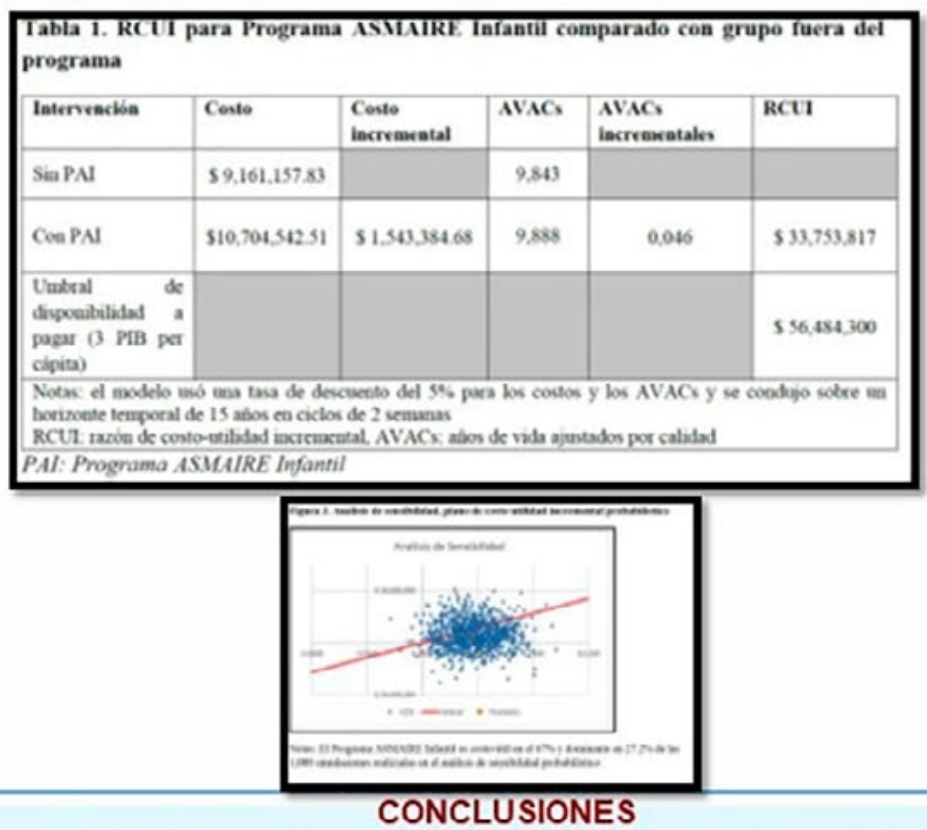

Una intervención integral para el manejo del asma resultó costo-útil para el control a largo plazo de la enfermedad. 